\title{
Minimizing the supply temperature at the district heating plant - dynamic optimization
}

\author{
Stanislav Chicherin ${ }^{1, *}$, Lyazzat Junussova ${ }^{2}$, and Timur Junussov ${ }^{2}$ \\ ${ }^{1}$ Omsk State Transport University (OSTU), 35 Marx av., Omsk, 644046, Russia \\ ${ }^{2}$ Almaty University of Power Engineering and Telecommunications (AUPET), 126 Baitursynov str., Almaty, 050013, Kazakhstan \\ Republic
}

\begin{abstract}
The constraint contains two elements, namely the heat losses and the electricity consumption for pumping at the producer. The aim was to achieve the lowest acceptable costs in an operation. The options with the supply temperature at the area starting point set to 80/60, then $60 / 40$, and eventually 50/30 (low temperature, $4^{\text {th }}$ generation district heating) were tested. The balance between the savings due to lower heat losses and the electricity consumption of pumps could be performed to assess the economic viability of the solution. This means that if the electricity price is sufficiently high, the model will always choose to minimize electricity consumption and thereby, maximise the profit from high temperature difference. Results concerning heat losses consider both experiences of proper insulation of pipes with variety of design outdoor temperatures (DOTs) and long term measurements from a pump station for district heating (DH) network in Canberra, Australia. We also noted that the heat energy tariffs and purchase price of electricity affect a lot optimal configuration of a DH system. For the best scenario, solutions are obtained that reach over $12 \%$ of the available saving potential after calculating 11 equations. Knowing that the policy is updated on a case study base, this is considered a promising result.
\end{abstract}

\section{Introduction}

When referring to a district heating (DH) network, additional energy loss from the pipes including electricity consumption for pumping and heat loss during thermal transmission must be added, as shown in [1].

The calculation method of pump power is introduced in [2]. Pump power depends directly on mass flow. In Ref. [3] mass flow has been obtained from a heating enterprise assuming the normal system operation. Zarin Pass et al. [4] provide upper and lower bounds on the density and associated distribution pumping losses of a more typical system. In Ref. [5], the energy consumption of electricity is obtained by referring to a monitoring system of a power plant as well. Romanchenko et al. [6] focus on the value of flexibility in terms of variable power-to-heat ratio of CHP plants i.e., opportunities for increased interplay between the electricity and DH heating systems. The role of DH in future energy systems is however still unclear, research questions of how district heating grids can make use of surplus electricity from intermittent electricity sources and how the access to conventional fuel sources such as waste and biofuels may develop further are crucial issues to investigate [7]. The electricity that constitutes marginal electricity is in reality different throughout the seasons and may also include more renewable energy in the future [8]. The thermal storages are treated as a part of the renewable heat sources in the model in [9]. To fulfil a peak demand more electricity is typically consumed. A possible way to mitigate this problem is to use the flexibility available in the network to decrease the variations in the load, which can be achieved by advanced control [10]. However, the negative way is increased number of operating hours for the heat boiler used when the heat demand is too low for the base load as reported by Andric et al. [11]. In Ref. [12] one of the indicators is defined as the ratio of the heating needs and electrical energy consumed, that is, in a first approximation the energy consumed by the compressor of a heat pump. Ma et al. [13] present the pump electricity saving in a commercial building, an office building, and a residential building, but not in an entire DH system.

In Ref. [14] ten controllable buildings represent nearly one-third of the total heat demand, including distribution losses in a network. The network heat losses are a major part of the energy involved, especially during the heating season [15]. Various applied temperature levels, insulation standards, and linear heat densities (heat sales per route length) create inevitable heat distribution losses between 5\% in Europe [16] and 50\% in Russia [17]. The high heat losses of heating networks in Russia are mainly due to improper design and poor construction of heat supply systems [18]. In EU it has become customary practice to use twin pipes dealing with smaller dimensions [19]. Twin pipes include two pipes within the same insulation and casing. This scheme

\footnotetext{
* Corresponding author: man_csv@hotmail.com
} 
has less heat loss from return pipes, as they are located within the temperature field of the supply pipe [19]. Moreover, the heat losses have a slight variation with a time, as a network temperature and the ground temperature have generally minor variations. Since a DH network also suffer from water losses due to leaks caused by pipeline failures [20], these techniques are relevant and are one of the heat losses reduction measures to implement into a DH system. Meanwhile, a reduction of $19.4{ }^{\circ} \mathrm{C}$ in the average return temperature results in reducing the heat network heat losses by $10 \%$ [21]. In Ref. [22] Chertkov\&Novitsky solve the advection-diffusion-losses equation, introduced and discussed in a setting of a single pipe.

Dahl et al. [23] suggest a control scheme that minimizes the supply temperature while ensuring security of supply. Badami et al. [24] also introduce objective function of an optimisation modelling approach for the planning of a DH network in terms of reliability. Because quantitative and accurate reliability evaluation of heating networks could not only determine weak sections of networks, but provide critical guidance for maintenance and optimization of the network in the design and operation phases [25]. In Ref. [26] the original network is aggregated before optimization process. Daily operation costs were taken as the objective function in study [27]. del Hoyo Arce et al. [28] pursue review of tools for modelling a DH network. Delangle et al. [29] enrich the pool of knowledge with highly flexible modelling approach which is capable of being adapted to other district energy schemes and modified to integrate more aspects and constraints. In paper [30], a tool for optimal energy management (not design) of a DH network is presented. According to [31] the question of how to optimally size the generation units must therefore involve an optimization routine which is able to quantify the optimum sizes for a given load curve. The objective of the paper is the dynamic optimization i. e. minimization the supply temperature at the producer. The constraint contains two elements, namely the heat losses and the electricity consumption for pumping at the producer.

\section{Materials and methods}

The aim was to achieve the lowest acceptable costs in an operation. The options with the supply temperature at the area starting point set to $80 / 60$, then $60 / 40$, and eventually 50/30 were tested.

The amount of heat delivered to the consumers can be controlled by changing the volume flow rate $\mathrm{G}$ or the supply temperature $\tau_{1}$ on a plant side.

$$
\mathrm{C}_{\mathrm{el}}=\operatorname{c\rho G}\left(\tau_{1}-\tau_{2}\right) \text {, }
$$

Circulation pump is a key component to ensure sufficient flow circulation of hot water from a DH plant to a substation. The electricity consumption of a pump in each time period can be determined by means of Eqs. (2)-(4) [2]

$$
\mathrm{C}_{\mathrm{el}}=\frac{\rho \mathrm{gQH}}{1000 \eta} \mathrm{yp}
$$

where

$$
\mathrm{H}=2 \frac{\mathrm{Rml}}{\rho \mathrm{g}} 1.1,
$$

and

$$
\mathrm{Rm}=6.68 \cdot 10^{-3} \mathrm{~K}^{1 / 4} \frac{\mathrm{G}^{2}}{\rho \mathrm{d}^{21 / 4}},
$$

The overall heat loss defined as the ratio of the heat flux to the thermal resistance (5)-(6) is given by [1]

$$
\begin{gathered}
\mathrm{Q}_{\text {loss }}=\frac{\mathrm{U} \pi \mathrm{d}_{0} \Delta \mathrm{x}\left(\tau_{1}-\mathrm{T}_{\text {soil }}\right)}{\mathrm{R}}, \\
\mathrm{R}=\frac{1}{\mathrm{~h}_{\mathrm{i}}}+\frac{\mathrm{r}_{4} \ln \left(\frac{\mathrm{r}_{2}}{\mathrm{r}_{1}}\right)}{\mathrm{k}_{1}}+\frac{\mathrm{r}_{4} \ln \left(\frac{\mathrm{r}_{3}}{\mathrm{r}_{2}}\right)}{\mathrm{k}_{2}}+\frac{\mathrm{r}_{4} \ln \left(\frac{\mathrm{r}_{4}}{\mathrm{r}_{3}}\right)}{\mathrm{k}_{3}}+\frac{1}{\mathrm{~h}_{0}}
\end{gathered}
$$

where $\mathrm{r} 1$ is the inner radius of pipe, $\mathrm{r} 2$ is the radius of insulation layer, $r 3$ is the radius of casing, and $r 4$ is the external radius of pipe, $\mathrm{k} 1, \mathrm{k} 2$ and $\mathrm{k} 3$ are the thermal conductivities of steel, insulation, casing and backfilling, $\mathrm{W} /(\mathrm{m} \mathrm{K})$, hi is the internal heat transfer coefficient; referring to [1], this means

$$
\mathrm{h}_{\mathrm{i}}=\frac{\mathrm{k}_{1}}{\mathrm{~d}_{\mathrm{i}}} \cdot 0.023 \operatorname{Re}^{0.8} \operatorname{Pr}^{0.4}
$$

We can then rewrite the external heat transfer coefficient in terms of $\left[^{1}\right]$ at each point to be

$$
\mathrm{h}_{0}=\frac{2 \mathrm{k}_{\text {soil }}}{\mathrm{d}_{0} \cos ^{-1}\left(\frac{2 \mathrm{Z}_{\mathrm{b}}}{\mathrm{d}_{0}}\right)}
$$

where ksoil is the thermal conductivity of the soil around the pipe, $\mathrm{W} /(\mathrm{m} \mathrm{K}), \mathrm{Zb}$ is the pipe centerline's depth below the surface, $\mathrm{m}$.

The object function of the proposed model is to search the minimum energy losses in a DH scheme

$$
\min \left[\sum_{\mathrm{t}=1}^{\mathrm{T}} \sum_{\mathrm{n}=1}^{\mathrm{N}} \frac{\mathrm{E}_{(\mathrm{t}, \mathrm{n})} \cdot \mathrm{C}_{\text {fuel }(\mathrm{n})}}{\eta_{(\mathrm{n})}}+\sum_{\mathrm{t}=1}^{\mathrm{T}} \sum_{\mathrm{n}=1}^{\mathrm{N}} \mathrm{P}_{(\mathrm{t}, \mathrm{pump})} \cdot \mathrm{C}_{\mathrm{el}(\mathrm{t})}\right]
$$

The minimum value should be obtained under the basic constraints of Eqs. (10)-(11) as well as the proposed simulation model

$$
\begin{gathered}
\sum_{\mathrm{n}=1}^{\mathrm{N}} \mathrm{E}_{(\mathrm{t}, \mathrm{n})} \geq \text { heat }_{\text {demand }(\mathrm{t})} \\
\min \mathrm{el}_{(\mathrm{t}, \text { pump })} \leq \mathrm{P}_{(\mathrm{t}, \text { pump })} \leq \max \mathrm{el}_{(\mathrm{t}, \mathrm{pump})}
\end{gathered}
$$


At these conditions, the design outdoor temperature (DOT) set is $\{-3.3 ;-2.6 ;-8.7\} \mathrm{C}$, whereas the annual average outdoor temperature is $5.81 \mathrm{C}$. The insulation is mineral wool with an identified thermal conductivity of $0.047 \mathrm{~W} / \mathrm{m} / \mathrm{K}$ [12]. The presented results apply the climate data from Canberra in Australia with the interval temperature distribution presented in [32].

\section{Results and discussion}

The heat demand on the distribution side is determined by eq. 1 and weather and must be met in all time steps by proper control of the flow [23]. The integrated model of a DH network calculates the heat losses and the cost of pumping as a function of the temperature level in the DH network pipes (Table 1).

Table 1. Values for Thermal Properties (Wh).

\begin{tabular}{|c|c|c|c|c|}
\hline Month & $\begin{array}{c}\text { Electricit } \\
\text { consumpt } \\
\text { ion } \\
(-3.3 \mathrm{C} \\
\text { DOT })\end{array}$ & $\begin{array}{c}\text { Heat } \\
\text { losses } \\
(-3.3 \mathrm{C} \\
\text { DOT })\end{array}$ & $\begin{array}{c}\text { Electricit } \\
\text { consumpt } \\
\text { ion } \\
(-2.1 \mathrm{C} \\
\text { DOT })\end{array}$ & $\begin{array}{c}\text { Heat } \\
\text { losses } \\
(-2.1 \mathrm{COT})\end{array}$ \\
\hline March & $4.33 \mathrm{E}+08$ & $7.53 \mathrm{E}+07$ & $4.33 \mathrm{E}+08$ & $7.53 \mathrm{E}+07$ \\
\hline April & $4.33 \mathrm{E}+09$ & $9.03 \mathrm{E}+08$ & $4.33 \mathrm{E}+09$ & $9.03 \mathrm{E}+08$ \\
\hline May & $4.50 \mathrm{E}+09$ & $1.11 \mathrm{E}+09$ & $4.54 \mathrm{E}+09$ & $1.11 \mathrm{E}+09$ \\
\hline June & $4.44 \mathrm{E}+09$ & $1.19 \mathrm{E}+09$ & $4.73 \mathrm{E}+09$ & $1.19 \mathrm{E}+09$ \\
\hline July & $4.84 \mathrm{E}+09$ & $1.19 \mathrm{E}+09$ & $5.17 \mathrm{E}+09$ & $1.19 \mathrm{E}+09$ \\
\hline August & $4.52 \mathrm{E}+09$ & $1.16 \mathrm{E}+09$ & $4.65 \mathrm{E}+09$ & $1.16 \mathrm{E}+09$ \\
\hline Sept. & $4.44 \mathrm{E}+09$ & $1.01 \mathrm{E}+09$ & $4.56 \mathrm{E}+09$ & $1.01 \mathrm{E}+09$ \\
\hline Total & $2.75 \mathrm{E}+10$ & $6.65 \mathrm{E}+09$ & $2.84 E+10$ & $6.65 E+09$ \\
\hline
\end{tabular}

Once we consider -3.3 degrees of outdoor temperature, instead of $-2.1 \mathrm{C}$, an extra $3.17 \%$ of primary energy saving can be saved. The heat loss of supply pipe is about $50 \%$ higher than that of same type in Dezhou, China $(24.5 \mathrm{~W} / \mathrm{m})$ [1]. The fact of $50 \%$ higher heat losses reflects that the pipe insulation may be somewhat aging or corroded by surrounding soil. Compared to the benchmark results of energy consumption, the proposed in Ref. [21] strategy shows the distribution losses accounting $3.6 \%$ of the total energy delivered, corresponding to an improvement of $10 \%$ for the entire DH network. The results presented by Romanchenko et al. [6] indicated that the decrease of heat demand proved to be the highest after the first year of renovation (2020), decreasing by as much as $52 \%$ of the reference value (2010). The solution to the optimization problem temperatures was reached when computed combination of supply and return temperatures fulfilled the stated constraints criteria. As can be seen from Fig. 1, the objective function (Eq. (9)) reaches its minimum value at DOT of $-8.7^{\circ} \mathrm{C}$.

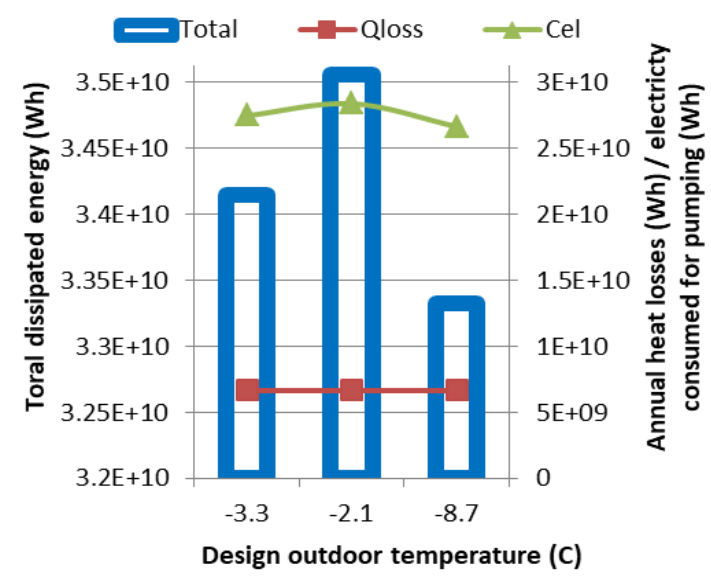

Fig. 1. Optimization results for different scenarios.

This means that if the electricity price is sufficiently high, the model will always choose to minimize electricity consumption and thereby, maximise the profit from high temperature difference. From [26], it can be seen that the heat losses and transport delays are possible to be captured within the optimization: the supply temperature at the periphery is lower and has some delay compared to the consumer close to the producer.

\section{Conclusions}

Results concerning heat losses consider both experiences of proper insulation of pipes with variety of DOTs and long term measurements from a pump station for $\mathrm{DH}$ network in Canberra, Australia. We also noted that the heat energy tariffs and purchase price of electricity affect a lot optimal configuration of a DH system.

For the best scenario, solutions are obtained that reach over $12 \%$ of the available saving potential after calculating 11 equations. Although we know that the policy is updated on a case study base we consider it as a promising result.

\section{References}

1. Wang, H., Meng, H. \& Zhu, T. New model for onsite heat loss state estimation of general district heating network with hourly measurements. Energy Convers. Manag. 157, 71-85 (2018).

2. Wu, Q., Ren, H., Gao, W., Weng, P. \& Ren, J. Coupling optimization of urban spatial structure and neighborhood-scale distributed energy systems. Energy 144, 472-481 (2018).

3. Chicherin, S. Low-temperature district heating distributed from transmission-distribution junctions to users: energy and environmental modelling. Energy Procedia 147, 382-389 (2018).

4. Zarin Pass, R., Wetter, M. \& Piette, M. A. A thermodynamic analysis of a novel bidirectional 
district heating and cooling network. Energy 144, 20-30 (2018).

5. Hou, J. et al. Implementation of expansion planning in existing district energy system: A case study in China. Appl. Energy 211, 269-281 (2018).

6. Romanchenko, D., Odenberger, M., Göransson, L. \& Johnsson, F. Impact of electricity price fluctuations on the operation of district heating systems: A case study of district heating in Göteborg, Sweden. Appl. Energy 204, 16-30 (2017).

7. Sernhed, K., Lygnerud, K. \& Werner, S. Synthesis of Recent Swedish District Heating Research. Energy (2018). doi:10.1016/j.energy.2018.03.028

8. Brange, L., Englund, J. \& Lauenburg, P. Prosumers in district heating networks - A Swedish case study. Appl. Energy 164, 492-500 (2016).

9. Wang, H., Wang, H., Zhou, H. \& Zhu, T. Modeling and optimization for hydraulic performance design in multi-source district heating with fluctuating renewables. Energy Convers. Manag. 156, 113-129 (2018).

10. Vandermeulen, A., van der Heijde, B. \& Helsen, L. Controlling district heating and cooling networks to unlock flexibility: A review. Energy (2018). doi:10.1016/j.energy.2018.03.034

11. Andrić, I., Fournier, J., Lacarrière, B., Le Corre, O. \& Ferrão, P. The impact of global warming and building renovation measures on district heating system techno-economic parameters. Energy (2018). doi:10.1016/j.energy.2018.03.027

12. Sartor, K., Lemort, V. \& Dewallef, P. Improved district heating network operation by the integration of high-temperature heat pumps. Int. J. Sustain. Energy 1-15 doi:10.1080/14786451.2017.1383409

(2017).

13. Chicherin, S., Volkova, A., \& Latõšov, E. GISbased optimisation for district heating network planning. Energy Procedia, 149, 635-641 (2018).

14. Geysen, D., De Somer, O., Johansson, C., Brage, J. \& Vanhoudt, D. Operational thermal load forecasting in district heating networks using machine learning and expert advice. Energy Build. 162, 144-153 (2018).

15. Noussan, M., Jarre, M. \& Poggio, A. Real operation data analysis on district heating load patterns. Energy 129, 70-78 (2017).

16. Werner, S. International review of district heating and cooling. Energy (2017). doi:10.1016/j.energy.2017.04.045

17. Chicherin, S. V. Unlocking a potential of district heating network efficient operation and maintenance by minimizing the depth of a trench system. Bull. Tomsk Polytech. Univ. Geo Assets Eng. 328, 49-56 (2017).

18. Chicherin, S. V. New approach to determination of corrosion damage degree of pipeline system elements. Bull. Tomsk Polytech. Univ. Geo Assets Eng. 327, 110-115 (2016).
19. Averfalk, H. \& Werner, S. Novel low temperature heat distribution technology. Energy 145, 526-539 (2018).

20. Valinčius, M., Vaišnoras, M. \& Kaliatka, A. Study and demonstration of pressure wave-based leak detection in a district heating network. Struct. Infrastruct. Eng. 14, 151-162 (2018).

21. Tunzi, M., Boukhanouf, R., Li, H., Svendsen, S. \& Ianakiev, A. Improving thermal performance of an existing UK district heat network: A case for temperature optimization. Energy Build. 158, 15761585 (2018).

22. Chertkov, M. \& Novitsky, N. N. Thermal Transients in District Heating Systems. Energy (2018). doi:10.1016/j.energy.2018.01.049

23. Dahl, M., Brun, A. \& Andresen, G. B. Using ensemble weather predictions in district heating operation and load forecasting. Appl. Energy 193, 455-465 (2017).

24. Badami, M., Fonti, A., Carpignano, A. \& Grosso, D. Design of district heating networks through an integrated thermo-fluid dynamics and reliability modelling approach. Energy 144, 826-838 (2018).

25. Shan, X., Wang, P. \& Lu, W. The reliability and availability evaluation of repairable district heating networks under changeable external conditions. Appl. Energy 203, 686-695 (2017).

26. Schweiger, G., Larsson, P.-O., Magnusson, F., Lauenburg, P. \& Velut, S. District heating and cooling systems - Framework for Modelica-based simulation and dynamic optimization. Energy 137, 566-578 (2017).

27. Deng, N. et al. Comparative analysis of optimal operation strategies for district heating and cooling system based on design and actual load. Appl. Energy 205, 577-588 (2017).

28. del Hoyo Arce, I. et al. Models for fast modelling of district heating and cooling networks. Renew. Sustain. Energy Rev. 82, 1863-1873 (2018).

29. Delangle, A., Lambert, R. S. C., Shah, N., Acha, S. \& Markides, C. N. Modelling and optimising the marginal expansion of an existing district heating network. Energy 140, 209-223 (2017).

30. Guelpa, E., Barbero, G., Sciacovelli, A. \& Verda, V. Peak-shaving in district heating systems through optimal management of the thermal request of buildings. Energy 137, 706-714 (2017).

31. Coss, S., Verda, V. \& Le-Corre, O. Multi-objective optimization of District Heating Network model and assessment of Demand Side Measures using the load deviation index. J. Clean. Prod. (2018). doi:10.1016/j.jclepro.2018.02.083

32. Chicherin, S. V. Comparison of a district heating system operation based on actual data - Omsk city, Russia, case study. Int. J. Sustain. Energy 2019, 38(6),603-614.doi:10.1080/14786451.2018.1548466 